\title{
Analysis of impurities occurring in a totally chlorine free-bleached Kraft pulp ${ }^{1}$
}

\author{
José C. del Río*, Ana Gutiérrez, Francisco J. González-Vila \\ Instituto de Recursos Naturales y Agrobiología de Sevilla, Consejo Superior de Investigaciones Científicas, P.O. Box 1052, \\ 41080 Seville, Spain
}

Received 28 July 1998; received in revised form 29 September 1998; accepted 9 October 1998

\begin{abstract}
A set of impurities (specks) occurring in a TCF (totally chlorine free)-bleached Kraft pulp of Eucalyptus globulus wood was studied. The impurities were Soxhlet extracted with acetone, and the extracts subsequently analyzed by gas chromatography (GC) and gas chromatography-mass spectrometry (GC-MS) using high-temperature capillary columns. The lipophilic fraction isolated from E. globulus wood extractives was also analyzed for comparison. The composition of the acetone extracts was very similar to that of E. globulus wood. Fatty acids, steroid hydrocarbons, sterols, steroid ketones and sterol esters, arising from E. globulus wood extractives survived the cooking and bleaching processes and accumulated in the pulp. On the other hand, the residue left after acetone extraction was studied by pyrolysis-GC-MS. The results indicated that it was composed of small particles of polyisoprene rubber. In conclusion, the speck impurities studied here seems to be composed of two different moieties, a lipophilic part arising from wood extractives and a core of small particles of synthetic polymers (polyisoprene rubber). (C) 1999 Elsevier Science B.V. All rights reserved.
\end{abstract}

Keywords: Eucalyptus globulus wood; TCF bleaching; Synthetic polymers; Kraft pulp; Polyisoprene rubber

\section{Introduction}

Wood extractives, a term that refers to a large number of wood compounds which are soluble in organic solvents, are known to give sticky deposits (the so-called pitch deposits) on pulp and pulp-mills. These compounds may deposit alone or with other components such as inorganic salts, filler, fiber, defoamers and coating binders during the pulping

\footnotetext{
*Corresponding author. Fax: +34-95-462-4002, E-mail: delrio@irnase.csic.es

${ }^{1}$ Presented at the 27th Scientific Meeting of the Group of Chromatography and Related Techniques of the Spanish Royal Society of Chemistry, Lugo, 8-10 July 1998.
}

and papermaking processes [1]. Pitch problems are likely to become more severe in the future due to high production rates that can cause overloading of washing equipments resulting in dirtier, more pitchladen stock. Likewise, increasing reuse of white waters and the trends towards complete closure of water circuits, is leading to an increase in pitch concentration which results in higher deposition. Synthetic polymers, on the other hand, are also usually found as contaminants in pulp and paper [2-4] since they may enter the process through machine breakage. The presence of impurities can severely impair product quality and is responsible for important economic losses in the pulp and paper industry. A break in production or defects in the final 
products may be very costly, and therefore a rapid characterization of the impurities occurring in pulp is important so that appropriate measures or treatments can be undertaken.

This work is part of a wider project aimed at identifying the constituents of pitch deposits in pulp and pulp-mills. In a previous paper, the composition of the pitch deposits accumulated in several parts of a pulp mill through an ECF (elementary chlorine free) bleaching sequence was studied [5]. In this paper, special attention has been paid to the analysis of a set of specks occurring on a TCF (totally chlorine free) bleached pulp. Acetone extracts of these impurities were studied by gas chromatography (GC) and gas chromatography-mass spectrometry (GC-MS) using high-temperature short capillary columns which have shown to be useful for the analysis of wood extractives [5-8]. On the other hand, the acetone insoluble moiety of the impurities was analyzed by analytical pyrolysis coupled to $\mathrm{GC}-$ MS (Py-GC-MS). This technique enables the rapid characterization of very small amount of material, and therefore is ideally suited to analyze the specks occasionally occurring in pulp $[2-4,9,10]$.

\section{Experimental}

\subsection{Description and extraction of the deposits}

The specks selected for this study were taken from the pulp produced at the ENCE (Empresa Nacional de Celulosas) pulp mill at Pontevedra, Spain. This pulp-mill uses eucalypt wood in a Kraft process with TCF bleaching. The specks occurring in pulp were hand-picked and separated from the cellulose fibers.

The specks (around $100 \mathrm{mg}$ ) were extracted in a Soxhlet apparatus with acetone (99\%, Panreac, Barcelona, Spain) for $24 \mathrm{~h}$. The acetone extracts were evaporated to dryness and redissolved in chloroform (Merck, Darmstadt, Germany) before analysis by GC and GC-MS. The residues left after extraction were analyzed by Curie-point flash pyrolysis-GC-MS.

\subsection{Gas chromatography and gas chromatography-mass spectrometry}

The GC analyses were performed in a HP-5890 using a short fused-silica capillary column (DB-5HT, $\mathrm{J} \& \mathrm{~W} ; 5 \mathrm{~m} \times 0.25 \mathrm{~mm}$ I.D., $0.1 \mu \mathrm{m}$ film thickness). The oven was heated from $100^{\circ} \mathrm{C}(1 \mathrm{~min})$ to $350^{\circ} \mathrm{C}$ at $15^{\circ} \mathrm{C} / \mathrm{min}$ and held for $3 \mathrm{~min}$. The injector (splitsplitless) and flame ionization detector temperatures were set at $300^{\circ} \mathrm{C}$ and $350^{\circ} \mathrm{C}$, respectively. The carrier gas was helium and the injection was performed in splitless mode.

The GC-MS analysis was performed on a Varian Saturn 2000 (ion trap detector) equipped with a fused-silica capillary column (DB-5HT, J \& W; 15 $\mathrm{m} \times 0.25 \mathrm{~mm}$ I.D., $0.1 \mu \mathrm{m}$ film thickness). The oven was heated from $120^{\circ} \mathrm{C}(1 \mathrm{~min})$ to $380^{\circ} \mathrm{C}$ at $10^{\circ} \mathrm{C} /$ $\min$ and held for $5 \mathrm{~min}$. The transfer line was kept at $300^{\circ} \mathrm{C}$. The injector was temperature programmed from $120^{\circ} \mathrm{C}(0.1 \mathrm{~min})$ to $380^{\circ} \mathrm{C}$ at a rate of $200^{\circ} \mathrm{C} /$ min and held until the end of the analysis. Helium was used as carrier gas. The compounds were identified by computer comparison of the mass spectra with those in the Wiley and NIST libraries, by mass fragmentography and when possible, by comparison with authentic standards.

A mixture of standard compounds (palmitic acid, stigmasta-3,5-diene, sitosterol, cholesteryl oleate and triheptadecanoin) supplied by Sigma (St. Louis, MO, USA) with a concentration range between 0.1 and $1.0 \mathrm{mg} / \mathrm{ml}$, was used to elaborate a calibration curve for the quantitation of wood extractives. The correlation coefficient was higher than 0.99 in all the cases. All peaks were quantified by peak area. Squalene was quantified by using the calibration curve for stigmasta-3,5-diene, while steroid ketones were quantified by using the sitosterol curve and the waxes by using the sterol esters curve.

\subsection{Curie-point flash-pyrolysis-gas chromatography-mass spectrometry}

The analysis was performed in a Varian Saturn 2000 GC-MS system coupled to a Curie-point pyrolyser (Horizon Instruments) using a fused-silica capillary column (DB-5, J \& W; $30 \mathrm{~m} \times 0.25 \mathrm{~mm}$ I.D., $0.25 \mu \mathrm{m}$ film thickness). Approximately $100 \mu \mathrm{g}$ of sample in finely divided form was deposited on a ferromagnetic wire, then inserted into the glass liner and immediately located in the pyrolyser and the pyrolysis carried out at $610^{\circ} \mathrm{C}$. The chromatograph was programmed from $40^{\circ} \mathrm{C}(1 \mathrm{~min})$ to $300^{\circ} \mathrm{C}$ at a 
rate of $6^{\circ} \mathrm{C} / \mathrm{min}$ and the final temperature held for 20 min. The injector, equipped with a liquid carbon dioxide cryogenic unit, was temperature programmed from $-30^{\circ} \mathrm{C}(1 \mathrm{~min})$ to $300^{\circ} \mathrm{C}$ at $200^{\circ} \mathrm{C} / \mathrm{min}$, while the $\mathrm{GC}-\mathrm{MS}$ interface was kept at $300^{\circ} \mathrm{C}$.

\section{Results and discussion}

Two different fractions could be distinguished in the specks collected from the TCF-bleached pulp, an acetone-soluble fraction and an acetone-insoluble residue. The quantitative estimation of each fraction was not possible due to the inherent problems associated with the collection of specks in pulp. Most of the specks are entrained within the pulp and therefore the collected specks always include different amounts of cellulose fibers from the pulp. In any case, the acetone-soluble fraction accounted for a significant part of the speck deposits $(>70 \%)$, while the rest corresponded to the acetone-insoluble residue.

\subsection{Analysis of the acetone extracts}

The chromatogram of the acetone extracts from the collected specks is shown in Fig. 1 and the relative composition is listed in Table 1 . The chromatogram and composition of E. globulus wood extractives are also shown for comparison. The great similarity between the composition of both extracts suggests that the acetone soluble fraction of the specks originates from the E. globulus wood extractives. The lipophilic constituents of E. globulus wood extractives accounts only for $0.26 \%$ of wood and the main compounds were sterols (32\% of total lipophilics), fatty acids (14\%), hydrocarbons (squalene and steroids; $7.5 \%$ ), steroid ketones (11\%), sterol esters (26\%) and triglycerides (6.7\%). Although these compounds are present in very small amounts in the wood, many of these species survive the pulping and bleaching processes and hence, accumulate and contribute to pitch deposition.

The main compounds present in the specks collected from the TCF Kraft pulp were sterols (36\% of the total extract), steroid hydrocarbons $(16 \%)$, fatty acids (13\%) and sterol esters $(21.3 \%)$. Triglycerides were not identified since they were hydrolyzed
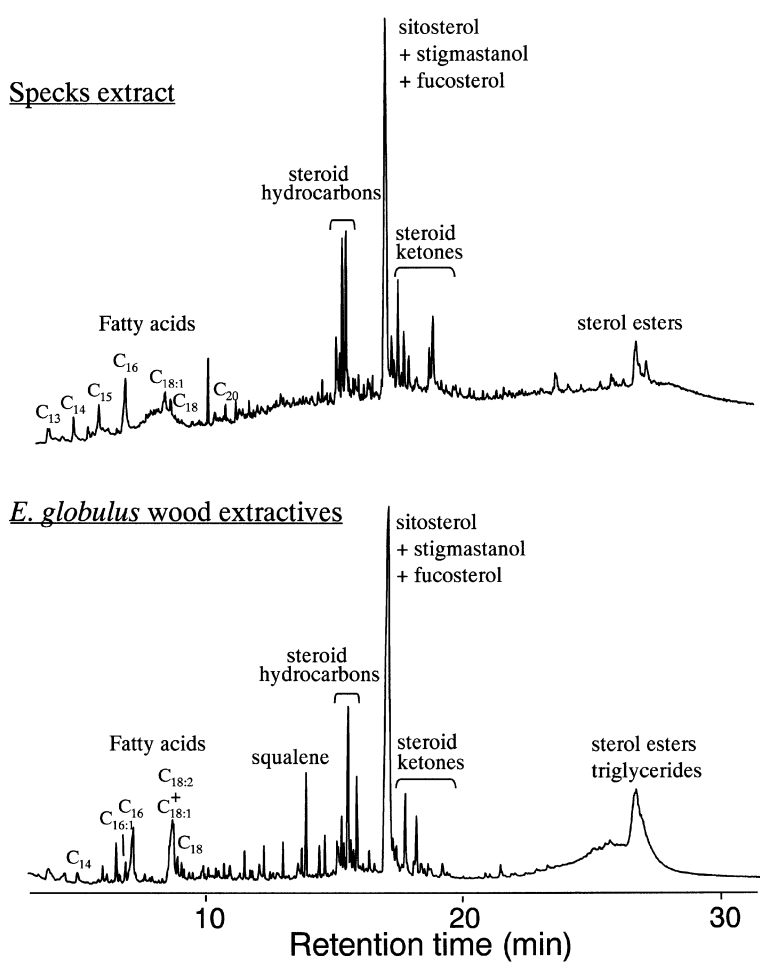

Fig. 1. Total ion chromatograms of the acetone extracts of the collected specks and Eucalyptus globulus wood extractives.

during the Kraft cooking, however, high amounts of fatty acids, including the unsaturated oleic and linoleic acids, were found. It is important to note the persistence of unsaturated fatty acids after the TCF bleaching with hydrogen peroxide since they are completely destroyed in more severe bleaching processes, such as bleaching with chlorine dioxide $[5,11]$. The composition of sterols were similar to that found in the E. globulus wood extractives, sitosterol being the most predominant. Sterol esters were also important components of the impurities extracts and are composed mainly by sitosterol and stigmastanol esters, with minor amounts of other sterol esters. No major structural changes of sterols and sterol esters have occurred during Kraft cooking and TCF bleaching with hydrogen peroxide. Similarly to the unsaturated fatty acids, it has already been observed that while the Kraft cooking and oxygen prebleaching stages do not affect the composition of sterols, ECF bleaching with chlorine dioxide de- 
Table 1

Relative abundance $(\%)$ of the main compounds identified in the extracts from E. globulus wood and from the specks collected in the selected TCF pulp

\begin{tabular}{|c|c|c|}
\hline Compounds & E. globulus wood & Specks in TCF pulp \\
\hline Fatty acids & 14.0 & 13.0 \\
\hline Tridecanoic acid & 0 & 0.5 \\
\hline Tetradecanoic acid & 0.4 & 1.7 \\
\hline Pentadecanoic acid & 0.3 & 1.6 \\
\hline 9-Hexadecenoic acid & 0.5 & 0 \\
\hline Hexadecanoic acid & 4.4 & 4.9 \\
\hline Heptadecanoic acid & 0.1 & 0.3 \\
\hline 9,12-Octadecadienoic acid & 3.8 & 0.2 \\
\hline 9-Octadecenoic acid & 2.0 & 1.6 \\
\hline Octadecanoic acid & 1.3 & 0.5 \\
\hline Nonadecanoic acid & 0 & 0.2 \\
\hline Eicosanoic acid & 0.3 & 0.4 \\
\hline Heneicosanoic acid & 0 & 0.2 \\
\hline Docosanoic acid & 0.4 & 0.6 \\
\hline Tricosanoic acid & 0 & $<0.1$ \\
\hline Tetracosanoic acid & 0.5 & 0.2 \\
\hline Hydrocarbons & 7.5 & 16.0 \\
\hline Squalene & 1.9 & 0 \\
\hline Stigmasta-3,5-diene & 4.2 & 6.4 \\
\hline Other steroid hydrocarbons & 1.4 & 9.6 \\
\hline Sterols & 32.0 & 36.0 \\
\hline Campesterol & 0.6 & $<0.1$ \\
\hline Sitosterol & 25.0 & 27.0 \\
\hline Stigmastanol & 3.0 & 7.0 \\
\hline Fucosterol & 1.2 & 0.8 \\
\hline Cycloartenol & 0.9 & 0.3 \\
\hline 24-Methylenecycloartenol & 0.5 & 0.7 \\
\hline Citrostadienol & 0.8 & $<0.1$ \\
\hline Steroid ketones & 11.0 & 11.0 \\
\hline Stigmasta-3,5-dien-7-one & 4.6 & 5.2 \\
\hline Stigmast-4-en-3-one & 4.8 & 2.5 \\
\hline Stigmastan-3-one & 0.6 & 1.7 \\
\hline Stigmasta-3,6-dione & 1.0 & 1.6 \\
\hline Waxes & 2.8 & 2.7 \\
\hline Sterol esters & 26.0 & 21.3 \\
\hline Sitosterol esters & 17.3 & 14.3 \\
\hline Stigmastanol esters & 3.5 & 5.0 \\
\hline Other sterol esters & 5.2 & 2.0 \\
\hline Triglycerides & 6.7 & 0 \\
\hline
\end{tabular}

grades completely the unsaturated sterol structures, such as sitosterol and sitosterol esters [5,11].

Likewise, the same steroid ketones and steroid hydrocarbons present in the E. globulus wood were also identified in the speck extract. The hydrocarbon squalene, found among the E. globulus extractives, could not be identified in the speck extracts. This compound was also absent in the extracts from the 
pulp mill deposits collected just after the Kraft cooking and oxygen prebleaching stages [5] which would suggest that this highly unsaturated hydrocarbon is affected by the Kraft cooking and/or bleaching stages. However, analysis of the evolution of wood extractives during the production of TCF pulp revealed that squalene survive these stages and is still present in the bleached pulp, although in very low amounts [12].

\subsection{Analysis of the insoluble residue}

The residues left after acetone extraction were analyzed by Py-GC-MS. The Py-GC-MS analyses were performed on several different specks, and all of them yielded similar pyrograms, showing the homogeneity of the collected impurities. Table 2 lists the compounds identified in the pyrograms with their relative abundance and the main fragments present in their mass spectra. The main compound released corresponded to dipentene, a compound with similar structure to limonene, and consisting of two isoprene units. Several isomeric compounds were also present, as well as their aromatic counterparts. Peaks corresponding to trimers, tetramers and pentamers were also identified in the pyrograms. Comparison with the Py-GC-MS data of various polymers published in the literature, confirmed that the speck residue consisted of a polyisoprene rubber $[13,14]$. Highmolecular-mass polyisoprenes occur in some higher plants and results from the 1,4 (head-to-tail) linkage of isoprenoid units. Polyisoprenes exclusively composed of cis units, i.e., natural rubber, and of trans units, i.e., gutta percha and balata, have both been identified in a number of species [15-17]. However, to our knowledge, they have not been detected in Eucalyptus spp. Most probably, the speck residue arise from rubber items from different parts of the mills, which are usually found as contaminants in pulp [2-4]. In fact, many different pieces of rubbers (polyisoprene rubber, polystyrene, polyethylene, poly- $\alpha$-methylstyrene, poly-butadiene) arising from machine breakage, and which were characterized by Py-GC-MS [18], are commonly found in the filters located along the pulping process in this pulp mill. Although the specks analyzed in this particular case were all made up of polyisoprene rubber, this does not exclude the fact that other synthetic polymers may also occasionally occur as impurities in pulp if they could enter the pulp stream. Analysis by Py-

Table 2

Main compounds identified in the pyrogram of the insoluble residue isolated from the collected specks, showing their relative abundance and the main fragments present in their mass spectra

\begin{tabular}{|c|c|c|c|c|c|}
\hline Scan & MS fragments & $M_{\mathrm{r}}$ & Compound & Formula & Relative abundance (\%) \\
\hline 450 & 91,92 & 92 & Toluene & $\mathrm{C}_{7} \mathrm{H}_{8}$ & 11 \\
\hline 696 & $91,105,106$ & 106 & Xylene & $\mathrm{C}_{8} \mathrm{H}_{10}$ & 10 \\
\hline 735 & $78,103,104$ & 104 & Styrene & $\mathrm{C}_{8} \mathrm{H}_{8}$ & 10 \\
\hline 815 & $105,121,136$ & 136 & Isoprene dimer & $\mathrm{C}_{10}^{0} \mathrm{H}_{16}^{\circ}$ & 3 \\
\hline 913 & $67,81,107,121,136$ & 136 & Isoprene dimer & $\mathrm{C}_{10} \mathrm{H}_{16}$ & 10 \\
\hline 946 & $91,103,117,118$ & 118 & Methylstyrene & $\mathrm{C}_{9} \mathrm{H}_{10}$ & 4 \\
\hline 970 & $67,105,121,136$ & 136 & Isoprene dimer & $\mathrm{C}_{10} \mathrm{H}_{16}$ & 3 \\
\hline 1050 & $107,121,136$ & 136 & Isoprene dimer & $\mathrm{C}_{10} \mathrm{H}_{16}$ & 5 \\
\hline 1098 & $67,81,95,107,121,136$ & 136 & Dipentene (isoprene dimer) & $\mathrm{C}_{10} \mathrm{H}_{16}$ & 100 \\
\hline 1215 & $91,117,132$ & 132 & Methylisopropenylbenzene & $\mathrm{C}_{10} \mathrm{H}_{12}$ & 2 \\
\hline 1276 & $91,105,119,134$ & 134 & Methylisopropylbenzene & $\mathrm{C}_{10} \mathrm{H}_{14}$ & 3 \\
\hline 1326 & $91,105,121,136$ & 136 & Isoprene dimer & $\mathrm{C}_{10} \mathrm{H}_{16}$ & 1 \\
\hline 1355 & $91,105,121,136$ & 136 & Isoprene dimer & $\mathrm{C}_{10} \mathrm{H}_{16}$ & 2 \\
\hline 1990 & $81,107,119,163,189,204$ & 204 & Isoprene trimer & $\mathrm{C}_{15} \mathrm{H}_{24}$ & 3 \\
\hline 2046 & $95,107,121,161,189,204$ & 204 & Isoprene trimer & $\mathrm{C}_{15} \mathrm{H}_{24}$ & 4 \\
\hline 2117 & $81,105,119,161,189,204$ & 204 & Isoprene trimer & $\mathrm{C}_{15} \mathrm{H}_{24}$ & 3 \\
\hline 2994 & $93,107,121,134,229,272$ & 272 & Isoprene tetramer & $\mathrm{C}_{20} \mathrm{H}_{32}$ & 2 \\
\hline 3095 & $93,107,121,161,229,272$ & 272 & Isoprene tetramer & $\mathrm{C}_{20} \mathrm{H}_{32}$ & 1 \\
\hline 4506 & $81,97,111,125,139,340$ & 340 & Isoprene pentamer & $\mathrm{C}_{25} \mathrm{H}_{40}$ & 12 \\
\hline 4639 & $81,97,111,125,139,340$ & 340 & Isoprene pentamer & $\mathrm{C}_{25} \mathrm{H}_{40}$ & 10 \\
\hline
\end{tabular}


GC-MS will provide a rapid means to identify the nature of the offending polymer and thus to trace back the source of contamination.

\section{Acknowledgements}

This research has been carried out with financial support from the Commission of the European Communities, Agriculture and Fisheries (FAIR) specific RTD Programme, CT95-0560, “Wood Extractives in Pulp and Paper Manufacture: Technical and Environmental Implications and Biological Removal". Samples were provided by Dr. J. Romero (ENCE, Pontevedra, Spain).

\section{References}

[1] W.E. Hillis, M. Sumimoto, in J. Rowe (Ed.), Natural Products of Woody Plants II, Springer-Verlag, Berlin, 1989, pp. 880-920.

[2] T.D. Crockett, A.A. Webb, L.G. Borchardt, D.B. Easty, J. Chromatogr. 407 (1987) 330.
[3] N. Dunlop-Jones, L.H. Allen, Tappi J. 71 (1988) 109.

[4] B.B. Sitholé, L.H. Allen, J. Pulp Paper Canada 20 (1994) 168.

[5] J.C. del Río, A. Gutiérrez, F.J. González-Vila, F. Martín, J. Romero, J. Chromatogr. A 823 (1998) 457.

[6] B.B. Sitholé, J.L. Sullivan, L.H. Allen, Holzforschung 46 (1992) 409.

[7] F. Örsa, B. Holmbom, J. Pulp. Pap. Sci. 20 (1994) J361.

[8] A. Gutiérrez, J.C. del Río, F.J. González-Vila, F. Martín, J. Chromatogr. A 823 (1998) 449.

[9] H.-L. Hardell, J. Anal. Appl. Pyrol. 27 (1993) 73.

[10] F.J. González-Vila, A. Gutiérrez, F. Martín, T. Verdejo, J. Anal. Appl. Pyrol. 40-41 (1997) 501.

[11] M.J. Jansson, P. Wormald, O. Dahlman, Pulp Paper Can. 96 (1995) 134.

[12] A. Gutiérrez, J.C. del Río, unpublished results.

[13] S.G. Roussis, J.W. Fedora, Rapid Commun. Mass Spectrom. 10 (1996) 82

[14] A. Krishen, R.G. Tucker, Anal. Chem. 46 (1974) 29.

[15] R.A. Buchanan, I.M. Cull, F.H. Otey, C.R. Russell, Econ. Bot. 32 (1978) 135.

[16] R.A. Buchanan, I.M. Cull, F.H. Otey, C.R. Russell, Econ. Bot. 32 (1978) 146.

[17] C.A. Nwadinigwe, Phytochemistry 27 (1988) 2135.

[18] J.C. del Río, A. Gutiérrez, J. Romero, F.J. González-Vila, F. Martín, presented at the 14th Int. Symp. on Analytical and Applied Pyrolysis, Neuherberg, 1998. 